Check for updates

Cite this: RSC Adv., 2020, 10, 17506

Received 1st March 2020

Accepted 29th April 2020

DOI: 10.1039/d0ra01980a

rsc.li/rsc-advances

\section{One pot fabrication of fluorescein functionalized manganese dioxide for fluorescence "Turn OFF- ON" sensing of hydrogen peroxide in water and cosmetic samples $\uparrow$}

\author{
Hassan Refat H. Ali, ${ }^{a}$ Ahmed I. Hassan, ${ }^{b}$ Yasser F. Hassan ${ }^{b}$ and Mohamed M. El- \\ Wekil (D) *a
}

\begin{abstract}
In recent decades, $\mathrm{H}_{2} \mathrm{O}_{2}$ has been promoted as a health indicator because its moderate to high levels can cause some health problems. Herein, we developed a new fluorescent nanoprobe for rapid, selective and sensitive detection of $\mathrm{H}_{2} \mathrm{O}_{2}$. The fluorescent nanoprobe is composed of fluorescein dye (FLS) as a fluorescent probe and $\mathrm{MnO}_{2}$ nanosheets $\left(\mathrm{MnO}_{2} \mathrm{NS}\right)$ as a quencher. In this study, $\mathrm{H}_{2} \mathrm{O}_{2}$ can reduce $\mathrm{MnO}_{2} \mathrm{NS}$ in the synthesized composite and release FLS, causing sufficient recovery of fluorescent signal related to the concentration of $\mathrm{H}_{2} \mathrm{O}_{2}$. The nanoprobe, with $\lambda_{\text {ex }} / \lambda_{\text {em }}$ at $495 / 515 \mathrm{~nm}$, has a linear range of 0.04-30 $\mu \mathrm{M}$, with a limit of detection (LOD) of $7.5 \mathrm{nM}$ and a limit of quantitation (LOQ) of $21 \mathrm{nM}$. The mean relative standard deviation (RSD) was $2.6 \%$ and the applicability of the method was demonstrated by the determination of $\mathrm{H}_{2} \mathrm{O}_{2}$ in water and cosmetic samples.
\end{abstract}

\section{Introduction}

Hydrogen peroxide $\left(\mathrm{H}_{2} \mathrm{O}_{2}\right)$, a colorless liquid usually produced as aqueous solutions of various strengths, is used principally for bleaching cotton and other textiles and wood pulp, in the manufacture of other chemicals, as a rocket propellant, in cosmetics and for medicinal purposes. ${ }^{1}$

From a biological point of view, $\mathrm{H}_{2} \mathrm{O}_{2}$ is formed in humans and other animals as a short-lived product in biochemical processes and is toxic to cells. The toxicity is due to oxidation of proteins, membrane lipids and DNA by the peroxide ions, so it can be a serious health hazard as a high level of $\mathrm{H}_{2} \mathrm{O}_{2}$ can precipitate cancer in the duodenum of mice after drinking water administration at $0.1 \%(\mathrm{w} / \mathrm{w}){ }^{2}$

The systemic effects of $\mathrm{H}_{2} \mathrm{O}_{2}$ result from its interaction with the intracellular catalase enzyme accompanied by the liberation of oxygen and water upon its decomposition. One milliliter of $3 \%$ hydrogen peroxide liberates $10 \mathrm{~mL}$ of oxygen. When the liberated oxygen exceeds the maximum blood solubility, intravascular oxygen embolism may occur. ${ }^{3}$

Repeated exposures to hydrogen peroxide vapor may cause chronic irritation of the respiratory tract and partial or complete lung collapse. Also, inhalation or ingestion of high

${ }^{a}$ Department of Pharmaceutical Analytical Chemistry, Faculty of Pharmacy, Assiut University, Assiut 71526, Egypt.E-mail: mohamed.mohamoud@ymail.com

${ }^{b}$ Department of Pharmaceutical Analytical Chemistry, Faculty of Pharmacy, Al Azhar University, Assiut 71526, Egypt

$\dagger$ Electronic supplementary information (ESI) available. See DOI: 10.1039/d0ra01980a concentrations of hydrogen peroxide can result in seizures, cerebral infarction, or cerebral embolism that may end in permanent neurological deficits or death. ${ }^{4}$

Therefore, the analytical methodology must be available for the determination of $\mathrm{H}_{2} \mathrm{O}_{2}$ to investigate its physiological functions and diagnosing diseases.

Several methods have been proposed for estimation of hydrogen peroxide such as colorimetry, ${ }^{5-7}$ fluorimetry, ${ }^{8-10}$ chemiluminescence, ${ }^{\mathbf{1 1 , 1 2}}$ chromatography ${ }^{\mathbf{1 3 - 1 6}}$ and electrochemistry. ${ }^{17-20}$ Some of these techniques such as chromatography needs highly expert trainer, time consuming and require expensive instrumentation.

The integration of fluorescent nanoprobes and other effective nanostructures in a cross-linked matrix has been widely utilized in the fabrication of typical sensors. The quenching effect induced by nanomaterials towards up-conversion nanoparticles and luminescent probes has already been used to improve fluorescence sensing platform. ${ }^{21-24}$ Nevertheless, a crucial drawback of expanding the practical application of these sensing frameworks is the narrowed range of materials for switching the fluorescence of probes.

Manganese dioxide $\left(\mathrm{MnO}_{2}\right)$ has possessed a considerable amount of current interest because manganese(II) is the twelfth most common element on the planet and the third most abundant transition element after iron and titanium. ${ }^{25}$ Manganese(II) ions act as cofactors in many functional enzymes with diverse mechanisms and a cornerstone in the oxygen-evolving units of photosynthetic tissues. ${ }^{26}$ Additionally, $\mathrm{MnO}_{2}$ has structural diversity; nanosheets, nanorods, nanospheres, 
nanobelts, nanowires, nanotubes, nanofibers and so on, which moreover expand its applications in a varied range of fields. Among the various $\mathrm{MnO}_{2}$ nanostructures, nanosheets provide adequate specific surface areas and high surface-to-volume ratios, permitting facile physicochemical interaction between reactants and its active sites. $\mathrm{MnO}_{2} \mathrm{NS}$ can be internally reduced to $\mathrm{Mn}$ (II), which in turn is considered to be friendly from the environmental and health points of view. ${ }^{27}$ It is worth to mention that, most of the reported $\mathrm{MnO}_{2}$ NS based fluorescent sensors offer some limitations such as an expensive reagent, time-consuming, low sensitivity, and poor $\mathrm{MnO}_{2}$ NS dispersity and complicated synthesized process. ${ }^{28-32}$

Fluorescein (FLS) FLS has attracted great interest in the fabrication of nanoprobes because FLS has been commercially available and so, avoiding complex preparation of emissive nanomaterials. Moreover, FLS has many functional groups that can be easily functionalized with $\mathrm{MnO}_{2}$ NS. Besides, the aqueous solubility of FLS enables the determination of several analytes in watery environment. ${ }^{33}$ FLS modified $\mathrm{MnO}_{2}$ NS was reported for analysis that relied on the distance between them, which was regulated with adsorption or desorption from $\mathrm{MnO}_{2} \mathrm{NS}^{34}$

In the proposed sensing system, we successfully synthesized $\mathrm{MnO}_{2} \mathrm{NS}$ and fluorescein nanoprobe via a template-free, one step sonically treatment. The synthesized $\mathrm{MnO}_{2} \mathrm{NS}$, in turn quench the relative fluorescence intensity (RFI) of fluorescein dye through fluorescence resonance energy transfer mechanism (FRET).

In addition to being an efficient nanoquencher for the fluorescence nanoprobe, the synthesized $\mathrm{MnO}_{2} \mathrm{NS}$ can also act as recognition agent for $\mathrm{H}_{2} \mathrm{O}_{2}$ as the latter can provoke the decomposition of the $\mathrm{MnO}_{2} \mathrm{NS}$ which are selectively reduced into $\mathrm{Mn}^{2+}$, accompanying the dependent recovery of fluorescence intensity of FLS dye.

\section{Experimental}

\subsection{Reagent and materials}

Double distilled water (DDW) was used along the whole work. Fluorescein, glycine, ascorbic acid, sucrose, urea and ferric chloride were purchased from Alpha chemical, Mumbai. Cadmium nitrate and zinc sulfate were purchased from El-Nasr pharma, Egypt. Hydrogen peroxide, potassium permanganate and sodium thiosulfate were purchased from Adco pharma, Egypt. Maltose and copper sulfate were purchased from Lab Chemicals Trade - LCT, Egypt. Potassium hydrogen phosphate, magnesium chloride, calcium chloride, and ferrous sulfate were purchased from Oxford Laboratory Chemicals, India. Glutathione, cysteine, glucose and glucose oxidase enzyme R2 GOD 2701018 were purchased from Biomed Pharmaceutical industry, Egypt. Other reagents and chemicals were purchased from Modern Cairo For Chemicals - Chema Chems, Egypt. Oxygen water bottles $(10 \%, v / v)$ were purchased from Liza Company, Egypt. Bleach cream was purchased from Ox Light, My Way Skin Clinic Limited, Egypt.

The standard solution of $\mathrm{H}_{2} \mathrm{O}_{2}$ was prepared by diluting $5.5 \mathrm{~mL} \mathrm{H}_{2} \mathrm{O}_{2}$ to $500 \mathrm{~mL}$ with DDW. Phosphate buffer solution (PBS) was prepared via mixing $80 \mathrm{~mL}$ of $\mathrm{Na}_{2} \mathrm{HPO}_{4} 0.5 \mathrm{M}(35.5 \mathrm{~g}$ $\mathrm{Na}_{2} \mathrm{HPO}_{4} / 500 \mathrm{~mL}$ DDW) and $30 \mathrm{~mL}$ of $\mathrm{NaH}_{2} \mathrm{PO}_{4} 0.5 \mathrm{M} \mathrm{(30} \mathrm{g}$ $\mathrm{NaH}_{2} \mathrm{PO}_{4} / 500 \mathrm{~mL}$ DDW) that has been reconstituted to $500 \mathrm{~mL}$ by DDW and adjusted to $\mathrm{pH} 7$ by adding appropriate amounts of the $0.5 \mathrm{M} \mathrm{NaH}_{2} \mathrm{PO}_{4}$ solution. ${ }^{35}$

$\left(0.04 \mathrm{M} \mathrm{H}_{3} \mathrm{BO}_{3}, 2.04 \mathrm{~g} / 100 \mathrm{~mL}\right)$ was mixed with $(0.04 \mathrm{M}$ $\mathrm{H}_{3} \mathrm{PO}_{4}, 2.8 \mathrm{~mL}$ of $\left.85 \% \mathrm{H}_{3} \mathrm{PO}_{4} / 100 \mathrm{~mL}\right)$, and $\left(0.04 \mathrm{M} \mathrm{CH}_{3} \mathrm{COOH}\right.$, $2.3 \mathrm{~mL} / 100 \mathrm{~mL}$ ) and set to the proper $\mathrm{pH}$ with $\mathrm{NaOH}$ to obtain Britton-Robinson (B. R) buffer. ${ }^{36}$

\subsection{Instrumentation}

An Adwa AD11P pH-meter (Romania) was used to measure $\mathrm{pH}$ values. The UV-Vis and luminescence measurements were carried out by Shimadzu UV-Vis (1601/PC, Japan) and a SCINCO FS/2 FluoroMate (Korea) spectrometers, respectively. Fouriertransform infrared (FT-IR) spectra were carried out by Nicolet $^{\mathrm{TM}}$ iS ${ }^{\mathrm{TM}} 10 \mathrm{FTIR}$, Slovenia in the range of $400-4000 \mathrm{~cm}^{-1}$. The surface morphology images of FLS@ $\mathrm{MnO}_{2}$ NS was done by scanning electron microscope (SEM), Hitachi and Transmission Electron Microscope (TEM, JEM-100CX II, USA). The phase crystallinity profile of FLS@ $\mathrm{MnO}_{2} \mathrm{NS}$ was studied utilizing a Philips X-ray diffractometer $(1710 \mathrm{PW}, \mathrm{Cu} \mathrm{K} \alpha$ radiation $\lambda=$ $1.5405 \AA$, $40 \mathrm{kV}$ voltage, $30 \mathrm{~mA}$ current, and $0.06^{\circ} \mathrm{min}^{-1}$ scanning rate, UK). Elemental analysis was performed using OXFORD INA energy dispersive X-ray instrument (EDX). The

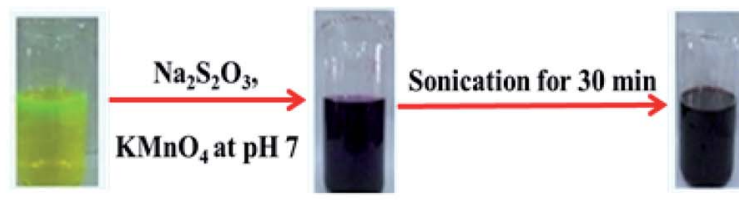

Centrifugation

Washing of precipitate

Drying at $60^{\circ} \mathrm{C}$ for $3 \mathrm{~h}$

Fluorescein (FLS)

Fluorescein/manganese dioxide nanosheets (FLS/ $\mathrm{MnO}_{2} \mathrm{NS}$ ) 
powder X-ray diffraction (PXRD) was scanned by Philips X-ray diffractometer PW 1710 supplied with $40 \mathrm{kV}$ operating applied voltage, $30 \mathrm{~mA}$ current, $0.06^{\circ} \mathrm{min}^{-1}$ scanning rate in the $2 \theta$ range of $\left(4-60^{\circ}\right)$ and $\mathrm{Cu} \mathrm{K} \alpha$ radiation $(\lambda=1.5405 \AA)$.

\subsection{Preparation of fluorescein modified manganese dioxide nanosheets (FLS@MnO ${ }_{2} \mathrm{NS}$ )}

The FLS@ $\mathrm{MnO}_{2}$ NS were synthesized by a facile ultrasonic coprecipitation route. Scheme 1 shows a schematic illustration of the synthesis process. Briefly, FLS $(0.01 \mathrm{~g})$ and of $\mathrm{Na}_{2} \mathrm{~S}_{2} \mathrm{O}_{3}$ $(0.03 \mathrm{~g})$ were dissolved in $200 \mathrm{~mL}$ PBS $\mathrm{pH} 7$ and then $0.2 \mathrm{~g}$ $\mathrm{KMnO}_{4}$ was added to the solution at room temperature. The output mixture was sonicated for $30 \mathrm{~min}$ until the entire discharge of the pink color of permanganate and a brown colloid was formed. Subsequently, the brown colloid allowed to centrifugation (4000 rpm for $30 \mathrm{~min}$ ) and separation of supernatant, and then the brown precipitate was collected and washed with DDW and absolute ethanol three times. After that, the precipitate was dried at $60{ }^{\circ} \mathrm{C}$ for $3 \mathrm{~h}$ in an electric oven and a purified $10 \mathrm{mg}$ was dispersed in $10 \mathrm{~mL} \mathrm{DDW}\left(1 \mathrm{mg} \mathrm{mL}^{-1}\right)$ for further characterization and application.

\subsection{Detection assay of $\mathrm{H}_{2} \mathrm{O}_{2}$ using FLS@MnO $\mathrm{MS}_{2}$}

$350 \mu \mathrm{L}$ FLS@ $\mathrm{MnO}_{2}$ NS aqueous solution $\left(0.35 \mathrm{mg} \mathrm{L}^{-1}\right)$ and 500 $\mu \mathrm{L}$ various concentrations of $\mathrm{H}_{2} \mathrm{O}_{2}$ were added to $150 \mu \mathrm{L} \mathrm{B}$. R. (pH 6.0). After $12 \mathrm{~min}$ at room temperature, the fluorescence spectra were observed under excitation of $495 \mathrm{~nm}$.

\subsection{Application to real samples}

$1.0 \mathrm{~mL}$ of oxygen water $10 \% \mathrm{v}$, v that is equivalent to $0.89 \mathrm{M}$, was diluted with DDW before application of the proposed fluorometric method.

$0.1 \mathrm{~g}$ of bleach cream was dissolved in $20 \mathrm{~mL}$ of ethyl alcohol and stirred until complete dissolution, and the volume was completed to $100 \mathrm{~mL}$ calibrated flask. Different aliquots of the prepared solution were taken and analyzed by the proposed method.

Ibrahimia conduit water (Assuit, Egypt) was filtered four times through a qualitative filter paper to remove the insoluble matters, preserved in high-quality clean plastic container, and stored at $4{ }^{\circ} \mathrm{C} .{ }^{37,38}$ The conduit water samples were spiked with known concentrations of $\mathrm{H}_{2} \mathrm{O}_{2}(5,10,15,20,25 \mu \mathrm{M})$ and were analyzed using the general procedure.

\section{Results and discussions}

\subsection{Strategy of $\mathrm{H}_{2} \mathrm{O}_{2}$ detection using FLS@ $\mathrm{MnO}_{2} \mathrm{NS}$}

The master plan for $\mathrm{H}_{2} \mathrm{O}_{2}$ determination was established on the capability to modulate the quenching of FLS luminescence that induced by $\mathrm{MnO}_{2}$ NS (Scheme 2).

An organic fluorophore, FLS as an energy donor, was adsorbed on the exterior surfaces of $\mathrm{MnO}_{2} \mathrm{NS}$, the nanosheets structure was primarily formulated thanks to the sonically reduction of permanganate by $\mathrm{Na}_{2} \mathrm{~S}_{2} \mathrm{O}_{3}$ in $\mathrm{PBS}$ ( $\mathrm{pH} 7$ ). Since $\mathrm{MnO}_{2}$ NS has a wide absorption band ranging from 390 to
$600 \mathrm{~nm}$ that remarkably interferes with the emission of FLS, the fluorescence of FLS can be efficiently faded by $\mathrm{MnO}_{2} \mathrm{NS}$.

Small quantities of $\mathrm{H}_{2} \mathrm{O}_{2}$ can mediate the redox pathway by which $\mathrm{MnO}_{2}$ turned into $\mathrm{Mn}^{2+}$ leading to the decomposition of the $\mathrm{MnO}_{2}$ NS accompanied by fluorescence restoration (Fig. 1).

The aforementioned in situ redox can be exemplified as the following equation: ${ }^{31,39}$

$$
\mathrm{MnO}_{2}+\mathrm{H}_{2} \mathrm{O}_{2}+2 \mathrm{H}^{+} \rightarrow \mathrm{Mn}^{2+}+2 \mathrm{H}_{2} \mathrm{O}+\mathrm{O}_{2}
$$

\subsection{Characterization of FLS@ $\mathrm{MnO}_{2} \mathrm{NS}$}

The morphology of $\mathrm{MnO}_{2} \mathrm{NS}$ and the formed FLS@ $\mathrm{MnO}_{2} \mathrm{NS}$ was characterized by TEM which revealed a lamellar nanostructure with large irregular folds, showing 2D morphology with a huge surface area. Furthermore, FLS/ $\mathrm{MnO}_{2}$ NS were observed with thicker and less transparent flakes that may due to FLS conjugation $\mathrm{MnO}_{2}$ NS. These multiple folds provide high relevance due to their high surface area available for short transport paths for electrons and ions ${ }^{40}$ (Fig. 2).

Moreover, the surface morphology of the formed FLS@MnO 2 NS was examined by SEM and the micrographs demonstrated high morphological purity. The film surface is compact and well wrapped with fine and disparate shaped grains (Fig. 3). Also, it

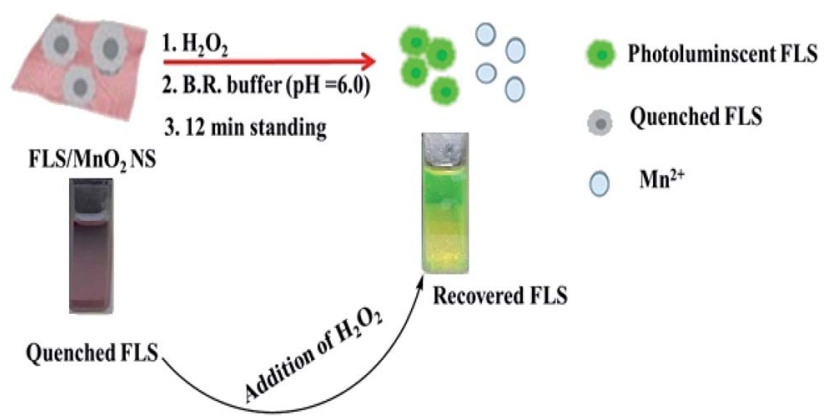

Scheme 2 Principle for $\mathrm{H}_{2} \mathrm{O}_{2}$ detection using $\mathrm{FLS} \mathrm{AMnO}_{2} \mathrm{NS}$.

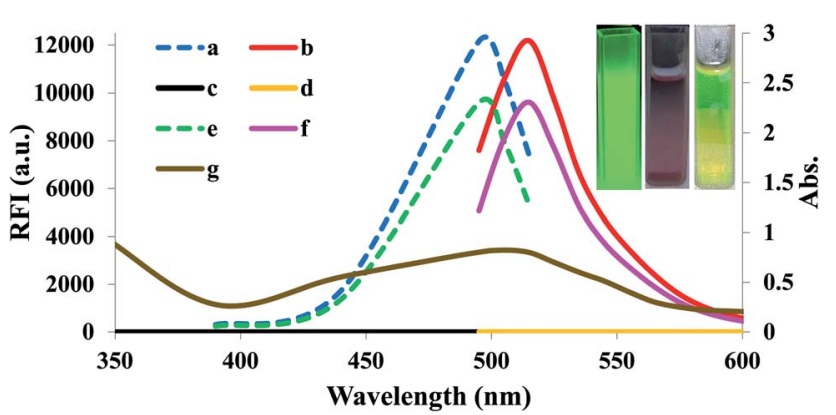

Fig. 1 Overlay spectra of (a) excitation of unreacted FLS, (b) emission of unreacted $\mathrm{FLS}$, (c) excitation of $\mathrm{FLS}\left(\mathrm{MnO}_{2} \mathrm{NS}\right.$ (blank), (d) emission of FLS@MnO $2 ~ N S$ (blank), (e) excitation of FLS@MnO $\mathrm{NS}_{2} \mathrm{~N} 20 \mu \mathrm{M} \mathrm{H}_{2} \mathrm{O}_{2}$, (f) emission of $\mathrm{FLS} @ \mathrm{MnO}_{2} \mathrm{NS}\left(2 \mathrm{O} \mu \mathrm{M} \mathrm{H}_{2} \mathrm{O}_{2}\right.$ while (g) is the absorbance of $\mathrm{FLS} \mathrm{aMnO}_{2} \mathrm{NS}$. Inset: observable fluorescence images of unmodified fluorescein (left), $\mathrm{FLS} \mathrm{aMnO}_{2} \mathrm{NS}$ (middle) and $\mathrm{FLS} \mathrm{aMnO}_{2} \mathrm{NS}_{2} 20$ $\mu \mathrm{M} \mathrm{H}_{2} \mathrm{O}_{2}$ (right) under the portable UV lamp. 

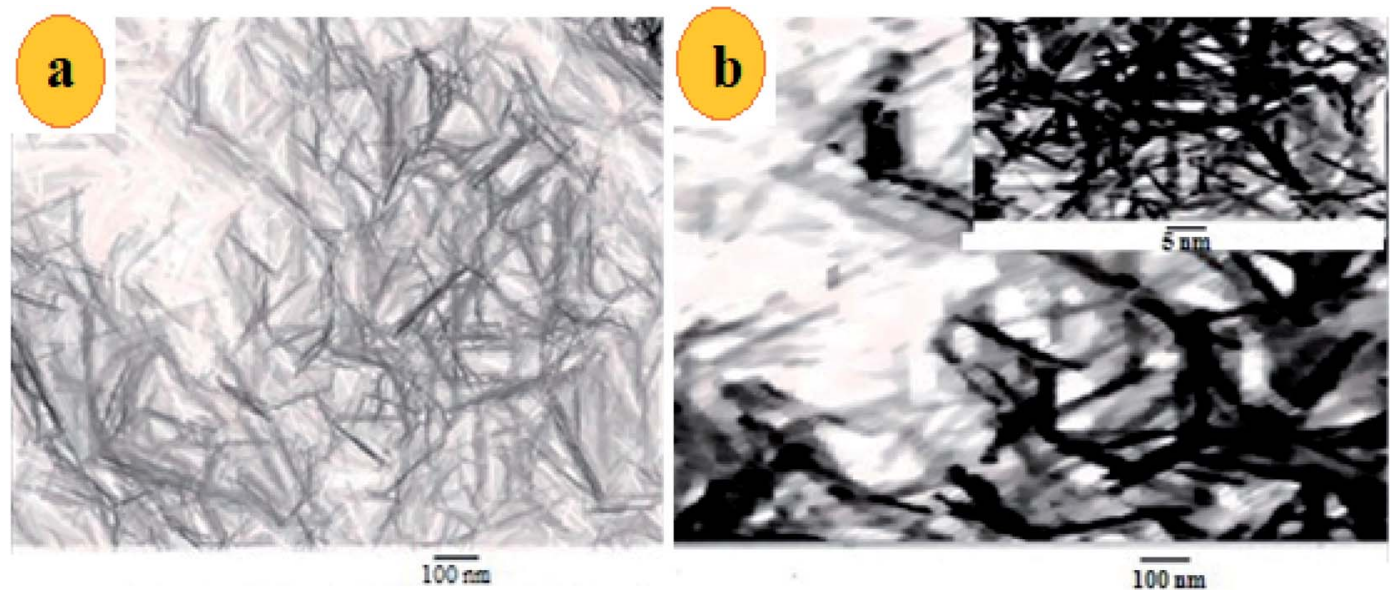

Fig. 2 TEM images of (a) ultrathin $\mathrm{MnO}_{2} \mathrm{NS}$ and (b) $\mathrm{FLS}\left(\mathrm{MnO}_{2}\right.$ nanocomposite at $100 \mathrm{~nm}$ and inset of (b) is a higher magnification.

is seen the surface looks highly porous which offers a large surface area. The high porosity and large surface area of films provide facile oncoming in the redox process and result in a high packing density of the active material. Nano-sized material limits the electron diffusion path which offers helpful support in the redox reaction. Such type of morphology leads to the porous volume, which provides the structural foundation for the high specific performance and the nanocomposite can be used as a cheap high potential catalyst in organic oxidation reactions. ${ }^{41}$

The phase purity and crystal structure of $\mathrm{MnO}_{2}$ NS were inspected by PXRD. As presented in Fig. 3, the diffraction peaks which appeared at $2 \theta=12.7^{\circ}, 18.1^{\circ}, 28.8^{\circ}, 37.5^{\circ}, 42.1^{\circ}, 57.2^{\circ}$, and $60.3^{\circ}$ matched well with the diffraction peaks of (110), (200), (310), (211), (301), (600), and (521) crystal planes of $\alpha$ $\mathrm{MnO}_{2}$, the PXRD pattern with sharp and intense peaks refers to a good crystallinity for the $\alpha-\mathrm{MnO}_{2}$ in the composite. ${ }^{42,43}$

Comparison of the PXRD patterns of unreacted FLS, untreated FLS/ $\mathrm{KMnO}_{4}$ and FLS@ $\mathrm{MnO}_{2}$ NS showed the absence of FLS peak in the FLS@ $\mathrm{MnO}_{2} \mathrm{NS}$ (Fig. 4), indicating an interaction between FLS and the $\mathrm{MnO}_{2} \mathrm{NS}^{44}$

The crosslinking of $\mathrm{MnO}_{2} \mathrm{NS}$ and FLS was examined by FTIR spectra of $\mathrm{MnO}_{2}$ nanostructure (with and without FLS incorporation) and the results are shown in Fig. 1S. $\dagger$ The two characteristic bands between 600 and $400 \mathrm{~cm}^{-1}$ attribute to the stretching collision of $\mathrm{O}-\mathrm{Mn}-\mathrm{O}$ and were blue-shifted in the nanocomposite sample by FLS. ${ }^{45}$

Furthermore, the absorption peaks at 899 and $1009 \mathrm{~cm}^{-1}$ represent the surface - $\mathrm{OH}$ groups of $\mathrm{Mn}-\mathrm{OH}$ for $\mathrm{MnO}_{2}$ NS which become wider in the nanocomposite product indicating the presence of FLS. ${ }^{46}$ In the high-frequency region, a broadband around $3400 \mathrm{~cm}^{-1}$ is observed which can be assigned to the stretching vibrations of adsorbed molecular water in $\mathrm{MnO}_{2}$ NS product and maximize thanks to stretching vibrations of the -OH group of FLS in nanostructure. ${ }^{47}$ The dominant peak at $1731 \mathrm{~cm}^{-1}$ can be assigned to the carbonyl stretching mode and the peaks at 1203 and $1117 \mathrm{~cm}^{-1}$ may be caused by $-\mathrm{C}-\mathrm{O}-\mathrm{H}$ stretching, implying the existence of residual hydroxyl groups ${ }^{44}$ (Fig. 1S†े).

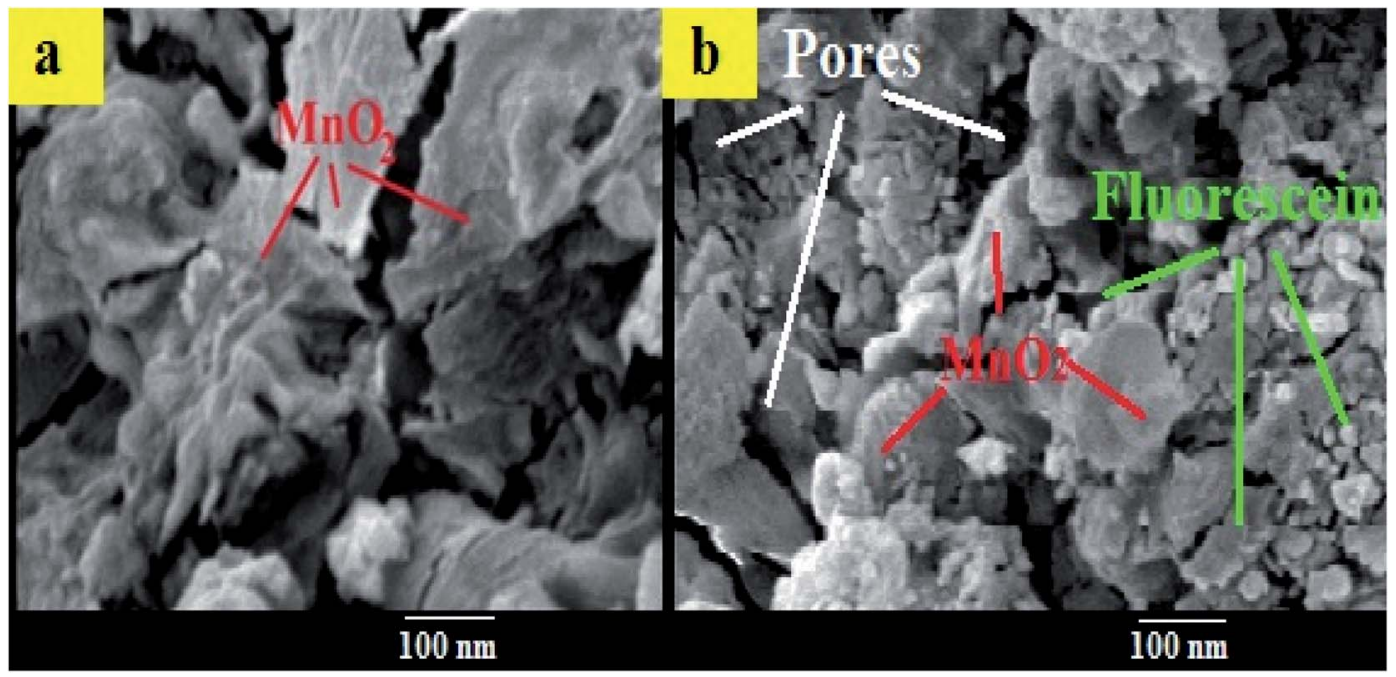

Fig. 3 SEM images of (a) $\mathrm{MnO}_{2} \mathrm{NS}$ (b) $\mathrm{FLS}_{\mathrm{aMnO}} \mathrm{NS}$. 


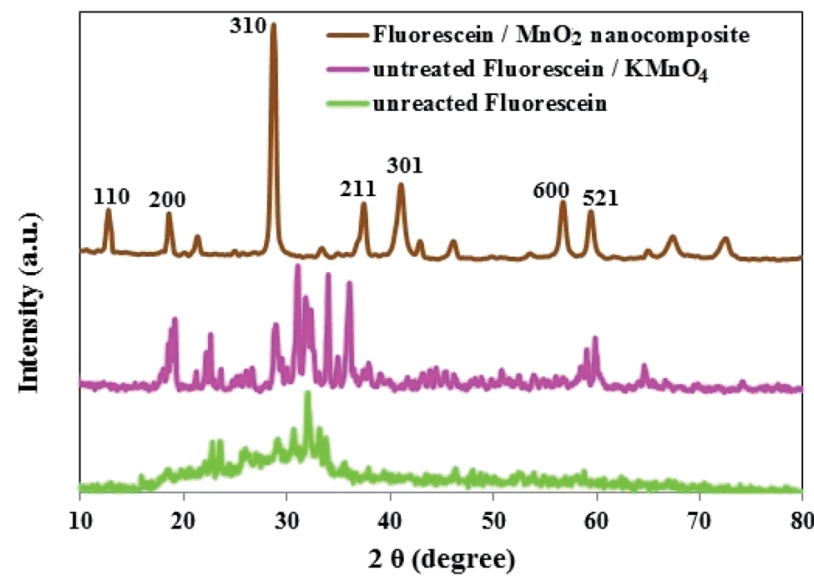

Fig. 4 PXRD patterns of unreacted FLS, untreated $\mathrm{FLS} / \mathrm{KMnO}_{4}$ and $\mathrm{FLS} \mathrm{AMnO} \mathrm{MS}_{2} \mathrm{NS}$

The EDX analysis of synthesized FLS@ $\mathrm{MnO}_{2}$ NS showed the presence of $\mathrm{Mn}$ and $\mathrm{O}$ in the sample (Fig. $2 \mathrm{~S} \dagger$ ). The chemical composition analysis using EDX confirmed the presence of Mn and $\mathrm{O}$ in the nanocomposite samples (Table $1 \mathrm{~S}^{\dagger}$ ) and was similar to the earlier studies of other researchers. ${ }^{48}$

UV-Vis spectra (Fig. 3S†) illustrate that unreacted FLS has a maximum absorbance of $490 \mathrm{~nm}$. The pink-colored solution after adding $\mathrm{KMnO}_{4}$, before sonication, exhibits maximum absorbance at $540 \mathrm{~nm}$. After sonication, the pink-colored product gradually converted into brown colloid indicating the synthesis of FLS@ $\mathrm{MnO}_{2}$ NS that acquire blue shifting from 590 to $495 \mathrm{~nm}$ that interfere with FLS emission (515 nm) leading to the respected quenching effect.

\subsection{Optimization of the experimental conditions}

Many buffers were checked to show the performance of FLS@ $\mathrm{MnO}_{2} \mathrm{NS}$ and the best results were obtained using B. R. buffer. Fig. 4Sa $\dagger$ shows the effect of the media $\mathrm{pH}$ on the fluorescence enhancement of FLS@ $\mathrm{MnO}_{2} \mathrm{NS}$ in the presence of $\mathrm{H}_{2} \mathrm{O}_{2}$.
A rise in $\mathrm{pH}$ from 3 to 5 results in the increased fluorescence enhancement efficiency of the FLS@ $\mathrm{MnO}_{2} \mathrm{NS}$ at $515 \mathrm{~nm}$ after the addition of $\mathrm{H}_{2} \mathrm{O}_{2}$, further increase in $\mathrm{pH}$ from 5 to 8 leads to a plateau, whereas a further increase in $\mathrm{pH}$ from 8 to 10 leads to a gradual decrease. Consequently, we selected 6.0 as the optimal $\mathrm{pH}$ for our study using B. R. as a buffering system.

The effect of the concentration of FLS@ $\mathrm{MnO}_{2} \mathrm{NS}$ on the fluorescence enhancement efficiency is displayed in Fig. 4Sb. $\dagger$ The fluorescence enhancement efficiency progressively increased with the concentration up to $0.3 \mathrm{mg} \mathrm{mL}^{-1}$. Exceeding that, the fluorescence intensity didn't affect. Therefore, $0.35 \mathrm{mg} \mathrm{mL}^{-1}$ was used as the optimal concentration for further performance.

The influence of incubation time on the fluorescence intensity of the system is shown in Fig. 4Sc. $\dagger$ The fluorescence enhancement became slow until reaching a steady state at $12 \mathrm{~min}$. A further increase of time didn't lead to any further perceptible enhancement. So, $12 \mathrm{~min}$ was chosen as the optimum incubation time.

\subsection{Calibration plot, LOD and LOQ}

After successfully fabricated the FLS@ $\mathrm{MnO}_{2} \mathrm{NS}$, the chance of $\mathrm{H}_{2} \mathrm{O}_{2}$ detection has then explored; we applied the developed procedure and inspected the fluorescence response signals at serial diverse $\mathrm{H}_{2} \mathrm{O}_{2}$ concentrations. At first, the fluorescence intensity of blank (replacing $\mathrm{H}_{2} \mathrm{O}_{2}$ loaded sample with doubledistilled water) is nearly negligible at the selected conditions while it was progressively increased with $\mathrm{H}_{2} \mathrm{O}_{2}$ incorporation. As the concentration of $\mathrm{H}_{2} \mathrm{O}_{2}$ increases, the fluorescence intensity increases (Fig. 5Sa $\dagger$ ).

The addition of $30 \mu \mathrm{M} \mathrm{H}_{2} \mathrm{O}_{2}$ led to a considerable enhancement, which indicated an almost complete recovery of free unreacted FLS. The recovery of fluorescence was related to the reduction of $\mathrm{MnO}_{2}$ which led to the degradation of the $\mathrm{MnO}_{2} \mathrm{NS}$ induced by $\mathrm{H}_{2} \mathrm{O}_{2}$ associated with the liberation of FLS. The fluorescence intensity values at $515 \mathrm{~nm}$ were rectilinear with the $\mathrm{H}_{2} \mathrm{O}_{2}$ concentrations in the range of $40 \mathrm{nM}$ to $30 \mu \mathrm{M},\left(R^{2}=\right.$

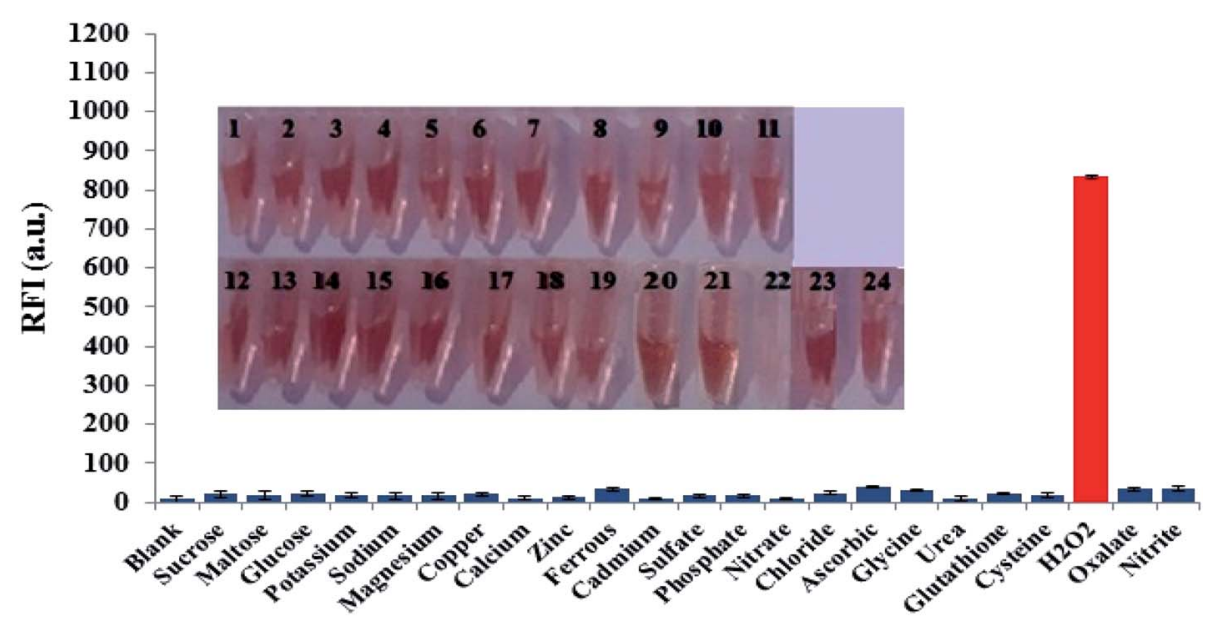

Fig. 5 Fluorescence responses of $\mathrm{FLS} \mathrm{MnnO}_{2} \mathrm{NS}$ in the presence of different interfering species (300 $\mu \mathrm{M}$ of each) at the selected conditions. Inset: photographs (from 1 to 24) corresponding to $X$-axis species of the diagram (from left to right). The concentrations of $\mathrm{H}_{2} \mathrm{O}_{2}(2 \mu \mathrm{M})$, error bars represent the standard deviations of three repetitive experiments. 
0.998) (Fig. 5Sb $\dagger$ ) with a mean relative standard deviation (RSD) of $2.6 \%$. Besides, the LOD [in terms of $3.3 \times$ standard deviation of the regression line $(\sigma) /$ slope $(S)$ ] was $7 \mathrm{nM}$ and the LOQ [in terms of $10 \times(\sigma) /(S)]$ was $21 \mathrm{nM}$.

\subsection{Selectivity study}

Possible interfering matters including various chemical, environmental and biological species were incubated with a solution of FLS@ $\mathrm{MnO}_{2} \mathrm{NS}$ at the selected experimental conditions. As shown in Fig. 5, only $\mathrm{H}_{2} \mathrm{O}_{2}$ can dissociate the nanocomposite, accompanied by discoloration of the brown, accordingly regenerate and enhance the fluorescence intensity. This investigation revealed that $300 \mu \mathrm{M}$ of a wide range of electrolytes and weakly reducing bio-agents didn't produce notable optical responses as well as didn't degrade the nanostructure as the color almost didn't change. It is worth mentioning that although some reports deduced the reduction of $\mathrm{MnO}_{2}$ NS by ascorbic acid but in our study the proposed method not affected significantly by ascorbic acid that may be attributed to the low acidity that not sufficient to oxidize ascorbic acid by $\mathrm{MnO}_{2} \mathrm{NS}$.

\subsection{Real samples analysis}

To test the analytical validity of this approach, the method was applied for the determination of $\mathrm{H}_{2} \mathrm{O}_{2}$ in pharmaceutical oxygen water, cosmetic cream and natural water using the procedures described in Section 2.5. As can be seen in Fig. 6S, $\dagger$ the emission spectrum for the analyzed pharmaceutical, cosmetic and natural samples is very identical to that exhibited in Fig. 5Sa. $\dagger$ This displays that the species existing in the inspected samples do not interfere in the estimation of $\mathrm{H}_{2} \mathrm{O}_{2}$ by the suggested approach. The analysis details of the real sample are signalized in (Table 1)

The recoveries of $\mathrm{H}_{2} \mathrm{O}_{2}$ fall in 86.8-106.5\%, implying that the synthesized nanoprobe can be efficiently used to determine $\mathrm{H}_{2} \mathrm{O}_{2}$ in real samples, the low value of $\mathrm{RSD} \%$ denotes the precision and feasibility of this method for determination of the respected analyte in real samples. To approve the accuracy of the proposed method, we statistically compare the results deduced by the current approach and other reported fluorometric method for the determination of $\mathrm{H}_{2} \mathrm{O}_{2}$ that was intended to be used to oxidize non-fluorescent coumarin to highly fluorescent 7-hydroxycoumarin. ${ }^{49}$ As can be seen from Table 1, all the calculated t-values are below the critical $t$ value of 2.571 for $95 \%$ confidence level and 5 degrees of freedom. Therefore, the accuracy of the method for the determination of the studied analytes is confirmed.

\subsection{Stability of FLS@ $\mathrm{MnO}_{2} \mathrm{NS}$}

The stability potential of the nanoprobe is of important value from an analytical point of view. The more stable a probe is, the more is its capacity for broad applications. Subsequently, the time-stability of the FLS@ $\mathrm{MnO}_{2}$ NS was examined after storing under normal conditions. After storing for one month, the material was collected by centrifugation and washed with double distilled water and ethanol, then dried in an oven at $60{ }^{\circ} \mathrm{C}$ for $3 \mathrm{~h}$ and measure the absorbance signal of the dispersed solution. Fig. $7 \mathrm{~S} \uparrow$ indicated that the absorbance response of $\mathrm{FLS} @ \mathrm{MnO}_{2} \mathrm{NS}$ was decreased slightly and no obvious change in color or morphology after storing for one month under normal conditions.

\subsection{Determination of glucose via enzymatic degradation to $\mathrm{H}_{2} \mathrm{O}_{2}$}

The proposed approach also proceeded for glucose sensing to examine the generality of the FLS@ $\mathrm{MnO}_{2} \mathrm{NS}$. From the standpoint of biochemistry, glucose can be catalytically oxidized by glucose oxidase enzyme and disintegrated into gluconic acid and $\mathrm{H}_{2} \mathrm{O}_{2}$, thus, glucose can be detected via the sensing of bioenzymatically developed $\mathrm{H}_{2} \mathrm{O}_{2}$. According to reported method, ${ }^{\mathbf{5 0}}$ and with slight modification, different concentrations of glucose solution $(5,10,15,20$ and $25 \mu \mathrm{M})$ was successively added to $100 \mu \mathrm{L} \mathrm{B}$. R. buffer $(\mathrm{pH}=6.0)$ and $100 \mu \mathrm{L}$ of glucose oxidase enzyme, followed by successively mixing and

Table 1 Determination of $\mathrm{H}_{2} \mathrm{O}_{2}$ in real samples using the proposed method and other reported method

\begin{tabular}{|c|c|c|c|c|c|c|}
\hline Samples & Taken $(\mu \mathrm{M})$ & Found $^{a}(\mu \mathrm{M})$ & Reported method $^{49}(\mu \mathrm{M})$ & $t$-Value & Recovery (\%) & $\operatorname{RSD}(\%)$ \\
\hline \multirow[t]{5}{*}{$\mathrm{H}_{2} \mathrm{O}_{2}$, oxygen water } & 5.0 & $4.3 \pm 0.019$ & 4.5 & 0.12 & $86.8 \pm 4.2$ & 3.2 \\
\hline & 10.0 & $10.1 \pm 0.023$ & 9.9 & 0.17 & $101 \pm 2.3$ & 1.4 \\
\hline & 15.0 & $14.1 \pm 0.015$ & 14.2 & 1.22 & $95.6 \pm 3.5$ & 4.2 \\
\hline & 20.0 & $21.3 \pm 0.022$ & 20.1 & 1.3 & $106.5 \pm 4.3$ & 2.7 \\
\hline & 25.0 & $24.3 \pm 0.034$ & 24.7 & 0.25 & $97.2 \pm 2.4$ & 3.9 \\
\hline \multirow[t]{5}{*}{ OX light, bleach cream } & 5.0 & $5.1 \pm 0.024$ & 5.8 & 0.12 & $101.7 \pm 2.1$ & 4.3 \\
\hline & 10.0 & $10.6 \pm 0.012$ & 10.9 & 0.38 & $105.8 \pm 1.1$ & 3.8 \\
\hline & 15.0 & $15.5 \pm 0.012$ & 15.9 & 1.13 & $103.3 \pm 3.3$ & 4.6 \\
\hline & 20.0 & $20.2 \pm 0.042$ & 20.4 & 1.23 & $101.1 \pm 2.9$ & 3.5 \\
\hline & 25.0 & $24.3 \pm 0.031$ & 25.3 & 2.14 & $97.4 \pm 3.6$ & 2.9 \\
\hline \multirow[t]{5}{*}{ Ibrahimia conduit water } & 5.0 & $5.3 \pm 0.026$ & 5.2 & 1.24 & $98.1 \pm 2.5$ & 1.3 \\
\hline & 10.0 & $10.3 \pm 0.034$ & 10.4 & 0.45 & $103 \pm 0.9$ & 3.7 \\
\hline & 15.0 & $15.5 \pm 0.021$ & 15.8 & 1.42 & $103.3 \pm 2.1$ & 2.9 \\
\hline & 20.0 & $21.2 \pm 0.008$ & 20.8 & 0.89 & $106 \pm 4.2$ & 2.4 \\
\hline & 25.0 & $25.8 \pm 0.003$ & 24.8 & 2.11 & $103.2 \pm 3.2$ & 1.8 \\
\hline
\end{tabular}

${ }^{a}$ Mean of three determinations. 
Table 2 Several reported sensors for the determination of $\mathrm{H}_{2} \mathrm{O}_{2}$

\begin{tabular}{|c|c|c|c|c|}
\hline Method & Range (M) & LOD (M) & $\mathrm{RSD} \%$ & Ref. \\
\hline Colorimetry & $2 \times 10^{-5}-8 \times 10^{-5}$ & $1 \times 10^{-5}$ & 2.4 & 6 \\
\hline Colorimetry & $1 \times 10^{-5}-8 \times 10^{-5}$ & $2 \times 10^{-6}$ & 4.1 & 7 \\
\hline $\mathrm{GC}$ & $1 \times 10^{-6}-1 \times 10^{-4}$ & $6 \times 10^{-7}$ & 4.7 & 15 \\
\hline Electrochemical & $4 \times 10^{-5}-4 \times 10^{-3}$ & $1 \times 10^{-5}$ & 3.4 & 51 \\
\hline Electrochemical & $1 \times 10^{-6}-1 \times 10^{-3}$ & $1 \times 10^{-7}$ & 4.3 & 52 \\
\hline Fluorimetry & $2 \times 10^{-8}-2 \times 10^{-5}$ & $5 \times 10^{-9}$ & 2.3 & 54 \\
\hline Fluorimetry & $1 \times 10^{-6}-3.5 \times 10^{-4}$ & $9 \times 10^{-7}$ & 2.9 & 31 \\
\hline Fluorimetry & $1 \times 10^{-6}-2 \times 10^{-4}$ & $3.3 \times 10^{-7}$ & 3.0 & 32 \\
\hline Fluorimetry & $4 \times 10^{-6}-1 \times 10^{-4}$ & $0.87 \times 10^{-6}$ & 2.9 & 55 \\
\hline Fluorimetry & $4 \times 10^{-8}-3 \times 10^{-5}$ & $7.5 \times 10^{-9}$ & 2.6 & This work \\
\hline
\end{tabular}
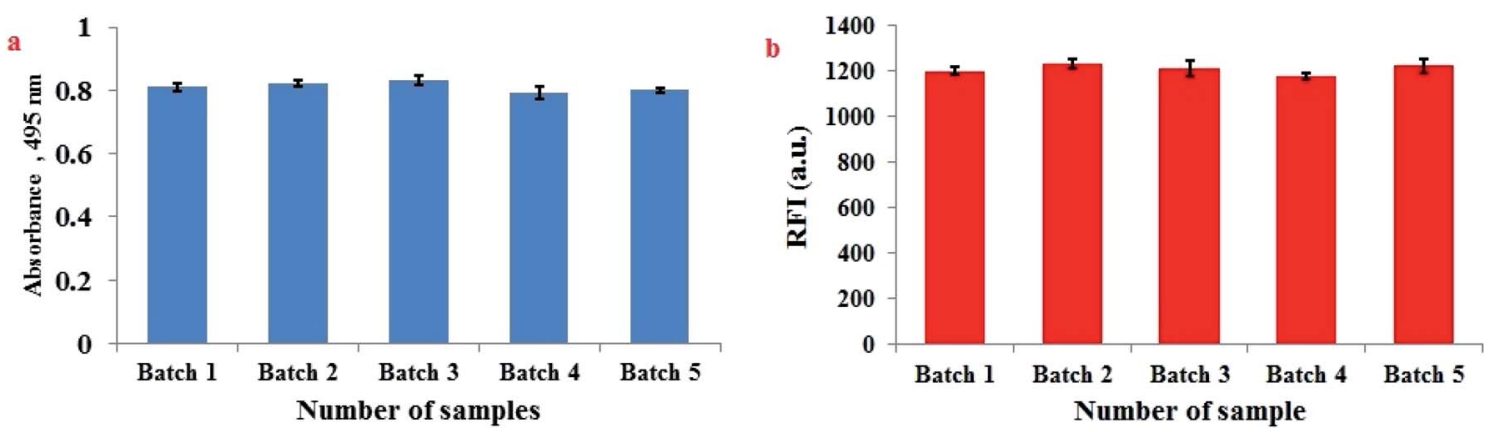

Fig. 6 Homogeneity of FLS $\mathrm{HnO}_{2} \mathrm{NS}$ and reproducibility of the synthesis procedure assessed by (a) spectrophotometric determination at $495 \mathrm{~nm}$ of five independent batches and (b) fluorescence detection of $3 \mu \mathrm{M} \mathrm{H}_{2} \mathrm{O}_{2}$ at five independent batches of FLS@MnO $2 \mathrm{NS}$.

incubation at room temperature for $5 \mathrm{~min}$ to obtain $\mathrm{H}_{2} \mathrm{O}_{2}$. Then, the dispersion of the prepared FLS@ $\mathrm{MnO}_{2} \mathrm{NS}(350 \mu \mathrm{L})$ was added into the above solution. The resulting mixture was successively incubated at room temperature for $12 \mathrm{~min}$ for the further fluorescence determination. As shown in Fig. $8 \mathrm{~S}, \dagger$ as the glucose concentration increased, the fluorescence intensity increased. The fluorescence intensity at $515 \mathrm{~nm}$ was rectilinear correlated to the glucose concentration $\left(5-25 \mu \mathrm{M}, R^{2}=0.9784\right)$ proving that the FLS@ $\mathrm{MnO}_{2}$ NS is generalizable and can be utilized to detect various $\mathrm{H}_{2} \mathrm{O}_{2}$ generating syntheses.

\subsection{Comparison of the proposed method with other methods}

Comparing the results in the proposed method with other published methods; from Table 2, it can be seen that the FLS@ $\mathrm{MnO}_{2} \mathrm{NS}$ can serve as a probe for the detection of $\mathrm{H}_{2} \mathrm{O}_{2}$ in a more wide concentration range, and can determinate them in a low concentration.

It is worth to mention that the proposed fluorometric method, if compared to other reported methods, has low detection limit and low \% RSD, indicating higher sensitivity and reliability of the proposed fluorometric method for analysis of $\mathrm{H}_{2} \mathrm{O}_{2}$. Moreover, the applicability of the fluorometric method was extended for the determination of the target analyte in different matrices.

\subsection{Homogeneity of FLS@ $\mathrm{MnO}_{2} \mathrm{NS}$ and reproducibility of} the synthesis procedure

The homogeneity of FLS@ $\mathrm{MnO}_{2}$ NS and reproducibility of synthesis procedure were performed through analysis of five independent batches of FLS@ $\mathrm{MnO}_{2} \mathrm{NS}$ spectrophotometrically at $495 \mathrm{~nm}$. Moreover, $3 \mu \mathrm{M} \mathrm{H}_{2} \mathrm{O}_{2}$ was repeatedly assayed by the proposed fluorimetric method in five separate sets using five independent batches of FLS@ $\mathrm{MnO}_{2}$ NS. The \% RSD did not exceed $3.89 \%$ which confirms that the synthesis procedure of FLS@ $\mathrm{MnO}_{2} \mathrm{NS}$ is homogenous and reproducible (Fig. 6).

\section{Conclusion}

In summary, we have developed FLS@ $\mathrm{MnO}_{2} \mathrm{NS}_{\text {platform via an }}$ uncomplicated one-step solution-phase passageway, by the reduction of potassium permanganate with sodium thiosulphate at room temperature with no aid of catalysts or templates and demanding no expensive and precise equipment, guarantees higher purity of the products, exceedingly diminishes the production cost and hence offers a great chance for analytical scale-up preparation of nanostructured materials. As a further matter, it is attractive that the as-synthesized FLS@ $\mathrm{MnO}_{2} \mathrm{NS}$ can be used as an effective nanoprobe for the detection of $\mathrm{H}_{2} \mathrm{O}_{2}$ with higher selectivity and sensitivity and applied to determine the respected analyte in real samples with 
acceptable results. The proposed nanoprobe has great potential for analytical and clinical investigation. In the meantime, this nanostructure is also generalizable and can be readily continued to sense several $\mathrm{H}_{2} \mathrm{O}_{2}$ generating substances as a logic gate application. The proposed protocol may provide a new insight to develop low-cost and sensitive methods for food, environmental, biological and clinical diagnostics applications.

\section{Conflicts of interest}

The authors declare that they have no known competing financial interests or personal relationships that could have appeared to influence the work reported in this paper.

\section{References}

1 B. E. Watt, A. T. Proudfoot and J. A. Vale, Toxicol. Rev., 2004, 23, 51-57.

2 M. Toyoda, Y. Ito, M. Iwaida and M. Fujii, J. Agric. Food Chem., 1982, 30, 346-349.

3 J. W. Sleigh and S. P. Linter, Br. Med. J., 1985, 291, 1706.

4 J. Sleigh and S. Linter, Br. Med. J., 1985, 291, 1706.

5 G. Eisenberg, Ind. Eng. Chem., Anal. Ed., 1943, 15, 327-328.

6 B. Zhou, J. Wang, Z. Guo, H. Tan and X. Zhu, Plant Growth Regul., 2006, 49, 113-118.

7 K. Nitinaivinij, T. Parnklang, C. Thammacharoen, S. Ekgasit and K. Wongravee, Anal. Methods, 2014, 6, 9816-9824.

8 H. Chen, H. Yu, Y. Zhou and L. Wang, Spectrochim. Acta, Part A, 2007, 67, 683-686.

9 Y. Gao, G. Wang, H. Huang, J. Hu, S. M. Shah and X. Su, Talanta, 2011, 85, 1075-1080.

10 A. L. Lazrus, G. L. Kok, J. A. Lind, S. N. Gitlin, B. G. Heikes and R. E. Shetter, Anal. Chem., 1986, 58, 594-597.

11 F. Shaw, Analyst, 1980, 105, 11-17.

12 D. Price, P. J. Worsfold, R. Fauzi and C. Mantoura, Anal. Chim. Acta, 1994, 298, 121-128.

13 S. M. Steinberg, Environ. Monit. Assess., 2013, 185, 37493757.

14 P. Gimeno, C. Bousquet, N. Lassu, A.-F. o. Maggio, C. Civade, C. Brenier and L. Lempereur, J. Pharmaceut. Biomed. Anal., 2015, 107, 386-393.

15 H.-C. Hu, H.-J. Jin and X.-S. Chai, J. Chromatogr. A, 2012, 1235, 182-184.

16 K. Kobayashi and S. Kawai, J. Chromatogr. A, 1982, 245, 339345.

17 L.-G. Zamfir, L. Rotariu, V. E. Marinescu, X. T. Simelane, P. G. L. Baker, E. I. Iwuoha and C. Bala, Sens. Actuators, B, 2016, 226, 525-533.

18 M.-Y. Hua, H.-C. Chen, C.-K. Chuang, R.-Y. Tsai, J.-L. Jeng, H.-W. Yang and Y.-T. Chern, Biomaterials, 2011, 32, 48854895.

19 H. Dai, W. Lü, X. Zuo, Q. Zhu, C. Pan, X. Niu, J. Liu, H. Chen and X. Chen, Biosens. Bioelectron., 2017, 95, 131-137.

20 H. Dai, Y. Chen, X. Niu, C. Pan, H. Chen and X. Chen, Biosens. Bioelectron., 2018, 118, 36-43.
21 Y. Wang, Z. Li, D. Hu, C.-T. Lin, J. Li and Y. Lin, J. Am. Chem. Soc., 2010, 132, 9274-9276.

22 M. Pumera and A. H. Loo, TrAC Trends Anal. Chem., 2014, 61, 49-53.

23 X. Yan, H. Li, X. Han and X. Su, Biosens. Bioelectron., 2015, 74, 277-283.

24 J. Li, Y. Li, S. A. Shahzad, J. Chen, Y. Chen, Y. Wang, M. Yang and C. Yu, Chem. Commun., 2015, 51, 6354-6356.

25 H. Veeramani, D. Aruguete, N. Monsegue, M. Murayama, U. Dippon, A. Kappler and M. F. Hochella, ACS Sustainable Chem. Eng., 2013, 1, 1070-1074.

26 R. A. Layfield, Chem. Soc. Rev., 2008, 37, 1098-1107.

27 M. Zhao, Y. Huang, Y. Peng, Z. Huang, Q. Ma and H. Zhang, Chem. Soc. Rev., 2018, 47, 6267-6295.

28 R. Deng, X. Xie, M. Vendrell, Y.-T. Chang and X. Liu, J. Am. Chem. Soc., 2011, 133, 20168-20171.

29 X.-L. Zhang, C. Zheng, S.-S. Guo, J. Li, H.-H. Yang and G. Chen, Anal. Chem., 2014, 86, 3426-3434.

30 Y. Yuan, S. Wu, F. Shu and Z. Liu, Chem. Commun., 2014, 50, 1095-1097.

31 J. Yuan, Y. Cen, X.-J. Kong, S. Wu, C.-L. Liu, R.-Q. Yu and X. Chu, ACS Appl. Mater. Interfaces, 2015, 7, 10548-10555.

32 T. Han, S. Zhu, S. Wang, B. Wang, X. Zhang and G. Wang, Microchim. Acta, 2019, 186, 269.

33 B. Wang, X. Guan, Y. Hu and Z. Su, J. Polym. Res., 2008, 15, 427-433.

34 C. Wang, W. Zhai, Y. Wang, P. Yu and L. Mao, Analyst, 2015, 140, 4021-4029.

35 A. A. Green, J. Am. Chem. Soc., 1933, 55, 2331-2336.

36 C. Mongay and V. Cerda, Anal. Chim. Acta, 1974, 64, 409-412.

37 M. M. El-Wekil, H. R. H. Ali, A. A. Marzouk and R. Ali, New J. Chem., 2018, 42, 9828-9836.

38 M. H. Mahnashi, A. M. Mahmoud, S. A. Alkahtani, R. Ali and M. M. El-Wekil, Spectrochim. Acta, Part A, 2020, 228, 117846.

39 S. Chen, Q. Jia, X. Zheng, Y. Wen, Y. Liu, H. Zhang, J. Ge and P. Wang, Sci. China Mater., 2018, 61, 1325-1338.

40 B. Mendoza-Sánchez and Y. Gogotsi, Adv. Mater., 2016, 28, 6104-6135.

41 H. Fan, F. Ran, X.-x. Zhang, H.-m. Song, X.-q. Niu, L.-b. Kong and L. Kang, Nano-Micro Lett., 2015, 7, 59-67.

42 Q. Zhu, H. Hu, G. Li, C. Zhu and Y. Yu, Electrochim. Acta, 2015, 156, 252-260.

43 L. Feng, Z. Xuan, H. Zhao, Y. Bai, J. Guo, C.-w. Su and X. Chen, Nanoscale Res. Lett., 2014, 9, 290.

44 Y. C. Lee, T. H. Lee, H. K. Han, W. J. Go, J. W. Yang and H. J. Shin, Photochem. Photobiol., 2010, 86, 520-527.

45 D. Jaganyi, M. Altaf and I. Wekesa, Appl. Nanosci., 2013, 3, 329-333.

46 S. Radhika and J. Thomas, J. Environ. Chem. Eng., 2017, 5, 4239-4250.

47 S.-G. Hwang, J.-E. Hong, G.-O. Kim, H. M. Jeong and K.-S. Ryu, ECS Solid State Lett., 2013, 2, M8-M11.

48 Z. Ren, Y. Li and J. Yu, iScience, 2018, 9, 138-148.

49 M. E. Abbas, W. Luo, L. Zhu, J. Zou and H. Tang, Food Chem., 2010, 120, 327-331.

50 Z. Huang, L. Zheng, F. Feng, Y. Chen, Z. Wang, Z. Lin, X. Lin and S. Weng, Sensors, 2018, 18, 2525. 
51 M. Guascito, E. Filippo, C. Malitesta, D. Manno, A. Serra and A. Turco, Biosens. Bioelectron., 2008, 24, 1057-1063.

52 D. Ye, H. Li, G. Liang, J. Luo, X. Zhang, S. Zhang, H. Chen and J. Kong, Electrochim. Acta, 2013, 109, 195-200.

53 A. Tahirović, A. Čopra, E. Omanović-Mikličanin and K. Kalcher, Talanta, 2007, 72, 1378-1385.
54 M. Abbas, W. Luo, L. Zhu, J. Zou and H. Tang, Food Chem., 2010, 120, 327-331.

55 K. Ning, G. Xiang, C. Wang, F. Huang, J. Liu, L. Zhang, M. Yan, B. Hu and W. Lei, Luminscence, 2020, DOI: 10.1002/bio.3799. 